\title{
Polysaccharides from Wolfberry Antagonizes Glutamate Excitotoxicity in Rat Cortical Neurons
}

\author{
Yuen-Shan Ho ${ }^{1,2}$, Man-Shan Yu ${ }^{1}$, Suet-Yi Yik $^{1}$, Kwok-Fai So ${ }^{1,2,3}$, \\ Wai-Hung Yuen ${ }^{4}$ and Raymond Chuen-Chung Chang $1,2,3^{*}$ \\ ${ }^{1}$ Laboratory of Neurodegenerative Diseases, Department of Anatomy, LKS Faculty of \\ Medicine; \\ ${ }^{2}$ Research Centre of Heart, Brain, Hormone and Healthy Aging, LKS Faculty of Medicine; \\ ${ }^{3}$ State Key Laboratory of Brain and Cognitive Sciences; \\ ${ }^{4}$ Department of Chemistry, \\ The University of Hong Kong, Pokfulam, Hong Kong SAR, CHINA
}

Keywords: Wolfberry / neuroprotection / glutamate / excitotoxicity / c-Jun N-terminal kinase

\section{*Correspondence address:}

Dr. Raymond C. C. Chang, Department of Anatomy, Faculty of Medicine, The University of Hong Kong, 21 Sassoon Road, Pokfulam, Hong Kong SAR, CHINA

Tel: (+852) 2819-9127; Fax: (+852) 2817-0857; E-mail: rccchang@hkucc.hku.hk 


\begin{abstract}
Glutamate excitotoxicity is involved in many neurodegenerative diseases including Alzheimer's disease (AD). Attenuation of glutamate toxicity is one of the therapeutic strategies in AD treatment. Wolfberry (Lycium barbarum) is a common ingredient in oriental cuisines. In recent years, there is a trend of using dried Wolfberry as food supplement and health product in U.K. and North America. A number of studies suggest that wolfberry has anti-aging properties. Previously, we have demonstrated that a fraction of polysaccharide from Wolfberry (LBA) provided remarkable neuroprotective effects against beta-amyloid peptide-induced cytotoxicity in primary cultures of rat cortical neurons. To investigate whether LBA can protect neurons from other pathological factors such as glutamate found in Alzheimer brain, we examined whether it can prevent neurotoxicity elicited by glutamate in primary cultured neurons. The glutamate-induced cell death as detected by lactate dehydrogenase (LDH) assay and caspase-3-like activity assay was significantly reduced by LBA at concentrations ranged from 10 to $500 \mu \mathrm{g} / \mathrm{ml}$. Protective effects of LBA were comparable to memantine, a non-competitive NMDA receptor antagonist. LBA provided neuroprotection even $1 \mathrm{~h}$ after exposure to glutamate. In addition to glutamate, LBA attenuated N-methyl-D-aspartate (NMDA)-induced neuronal damage. To further explore whether LBA might function as antioxidant, we used hydrogen peroxide $\left(\mathrm{H}_{2} \mathrm{O}_{2}\right)$ as oxidative stress inducer in this study. LBA could not attenuate the toxicity of $\mathrm{H}_{2} \mathrm{O}_{2}$. Furthermore, LBA did not attenuate glutamate-induced oxidation by using NBT assay. Western blot analysis indicated that glutamate-induced phosphorylation of c-jun N-terminal kinase (JNK) was reduced by treatment with LBA. Taken together, LBA exerted significant neuroprotective effects on cultured cortical neurons exposed to glutamate.
\end{abstract}




\section{Introduction}

Glutamate is an excitatory amino acid and plays important roles in neurotransmission. It is also involved in a wide array of physiological processes including synaptogenesis, neuronal plasticity, learning and memory (Miyamoto, 2006; Shigeri et al., 2004). In physiological conditions, the concentration of glutamate in synapses is tightly controlled. Abnormal high concentrations of glutamate result in neuronal cell damage, which can be found in brain injury, hypoxia, ischemia, Alzheimer's disease (AD), Parkinson's disease and Huntington's disease (Arundine and Tymianski, 2004; Coyle and Puttfarcken, 1993; Won et al., 2002).

Two major mechanisms have been proposed for the neurotoxicity of glutamate. The first one is glutamate-receptor mediated excitotoxicity, which is mainly contributed by the activation of ionotropic glutamate receptors. The subsequent influx of $\mathrm{Ca}^{2+}$ can cause both necrotic and apoptotic cell death (Choi et al., 1987; Hyrc et al., 1997). The second mechanism is the induction of oxidative stress by glutamate (Shih et al., 2006; Schubert and Piasecki, 2001). High concentrations of glutamate in synapses can inhibit the cysteine/glutamate antiporter $\mathrm{x}_{\mathrm{c}}{ }^{-}$; and therefore attenuating uptake of cysteine. Since cysteine is required for the synthesis of glutathione (GSH), depletion of glutathione by extracellular glutamate results in accumulation of oxidative stress and programmed cell death (Schubert and Piasecki, 2001; Tan et al., 1998; Tan et al., 2001).

As glutamate neurotoxicity is involved in the pathogenesis of $\mathrm{AD}$, reduction of glutamate-toxicity is one of the possible therapeutic targets (Pietrzik and Behl, 2005; Gardoni and $\mathrm{Di}, 2006)$. Several drugs targeting glutamate toxicity are under development for the treatment of $\mathrm{AD}$. An example is memantine, a non-competitive NMDA antagonist, for the 
treatment of moderate to severe AD (Golde, 2006). In fact, some compounds or extracts from daily food can also protect neurons against glutamate-toxicity. Curcumin is a principle polyphenol which is responsible for the yellow color of the Indian curry spice turmeric. Studies have shown that it protects primary cultured neurons from glutamate-induced cell death, probably by inhibiting PKC activity, and subsequent phosphorylation of NR1 of the NMDA receptor (Yazawa et al., 2006). The green tea extract EGCG may also provide protection against glutamate by enhancing glutamate uptake and S100B secretion from astrocytes (Abib et al., 2008). It is therefore possible to develop disease-modifying agent that have neuroprotective function against glutamate excitotoxicity from daily food.

Wolfberry, the fruits of Lycium barbarum, has long been used as a common ingredient in oriental cuisines. It has a high content of zeaxanthin, which probably enable it to improve and maintain vision. In recent years, there is a trend of using Wolfberry as food supplement and health product in U.K. and North America. For example, the juice of Wolfberry, called Goji juice, is a commercially available product which claims to be beneficial to our health and slow down aging. A recent randomized, double-blinded clinical study has shown that it can increase subjective feelings of general well-being and improves neurologic/psychologic performance (Amagase and Nance, 2008). Whether Goji juice is as beneficial as it claims remains a question, some research focused on the Wolfberry extracts and its different components demonstrated that they provided diverse biological effects. Recent evidence on its anti-aging effects have suggested that it is neuroprotective in various aging-associated pathological conditions (Chan et al., 2007; Chang and So, 2008; Ho et al., 2007; Li et al., 2007; Yu et al., 2005; Yu et al., 2006). The major active component from Wolfberry is polysaccharide. Previously, our laboratory has demonstrated that a fraction of polysaccharides from Wolfberry (LBA) elicits neuroprotective effects against beta-amyloid (A $\beta$ ) peptide 
toxicity (Ho et al., 2007; Yu et al., 2005). To further examine whether LBA can serve as disease-modifying agent against degeneration in $\mathrm{AD}$, we investigated its protective effects against glutamate excitotoxicity. It is possible that LBA may protect neurons against other Alzheimer's disease-related pathological conditions. We hypothesize that LBA exerts cytoprotective effects against glutamate toxicity. 


\section{Results}

\subsection{Protective effects of LBA against glutamate-induced cell death}

To examine the toxicity of glutamate, cortical neurons were exposed to 30 or $60 \mu \mathrm{M}$ glutamate. Cultured neurons have a normal turnover with baseline LDH of $12.5 \pm 0.5 \%$ of total lysis. Exposure to 30 or $60 \mu \mathrm{M}$ glutamate elevated $\mathrm{LDH}$ release to $2.7 \pm 0.2$ fold of control or $3.3 \pm 0.2$ fold of control, respectively (Fig 1c, 1e). Exposure to LBA markedly reduced glutamate neurotoxicity in concentration-dependent manner. LBA at $500 \mu \mathrm{g} / \mathrm{ml}$ significantly abrogated cell death-induced by glutamate (Fig 1c, 1e).

Glutamate also induced apoptotic cell death as indicated by activation of caspase-3. The specific activity of caspase- 3 was $0.042 \pm 0.007 \mathrm{pmol} / \mathrm{min} / \mu \mathrm{g}$ of protein in our control group. Glutamate at 30 or $60 \mu \mathrm{M}$ elevated activities of caspase- 3 by $1.6 \pm 0.1$ or $1.8 \pm 0.1$ fold of control, respectively (Fig. 1d, 1f). Treatment of LBA significantly decreased glutamatetriggered activity of caspase-3. The effective dosages of LBA to attenuate glutamate toxicity were ranged from 10 to $500 \mu \mathrm{g} / \mathrm{ml}$, which was wider than that observed by LDH assay. One has to notice that activation of caspase- 3 is on of the processes in apoptosis, while LDH is the end-product assay of necrosis. Therefore a high dose of LBA is required for reducing LDH release. We did not have any intention to makes correlation between LDH release and capsase-3 activity, but serving as index for different mode of death (Baethmann et al., 1996).

The protective effects of LBA on glutamate-induced cell death were supported by examining neuronal morphology. Representative images showing the protective effects of LBA against $24 \mathrm{~h}$ of exposure to glutamate are depicted in Fig. 2. Exposure to glutamate led to shrinkage of cell body and breakage of neurites (Fig. 2b and 2c). In LBA-treated groups (Fig. 2 e and 2f), neuronal cell maintained their integrity and fasciculation of neurites. 
LBA itself had no significant effect on LDH and caspase-3 activity (Fig. 1a and 1b); and there was no obvious morphological difference between the control and LBA groups (Fig. $2 d)$.

\subsection{Comparison of LBA and memantine in attenuating glutamate excitotoxicity}

To examine the effectiveness of LBA in glutamate-induced cell death, we used memantine as positive control. Memantine is a drug approved by the European Union and the U.S. Food and Drug Administration (FDA) for the treatment of AD. The mechanism for its action is partly because it is a non-competitive and low-affinity NMDA antagonist (Lipton, 2005; Johnson and Kotermanski, 2006). The neuroprotective effects of LBA and memantine against glutamate-excitotoxicity were compared. We used memantine for comparison because we would like to know the efficacy of LBA in attenuating glutamate toxicity. Preliminary trials were carried out to determine the most effective and non-toxic dosages for memantine against glutamate toxicity (data not shown). The maximum dosage of memantine used in this study was $1 \mu \mathrm{M}$, which is the usual therapeutic plasma concentration in $\mathrm{AD}$ patients (Kornhuber and Quack, 1995; Parsons et al., 2008). Fig. 3a shows the protective effects of LBA and memantine against glutamate-induced LDH release. Both LBA and memantine could significantly attenuate release of $\mathrm{LDH}$, and their protective effects were comparable. Similar results were observed in $30 \mu \mathrm{M}$ glutamate-mediated activation of caspase-3 (Fig. 3b). Both LBA and memantine could almost completely reduce activity of caspase- 3 triggered by $30 \mu \mathrm{M}$ glutamate. However, only LBA provided protection against $60 \mu \mathrm{M}$ glutamate as indicated by the reduction of level of caspase- 3 from $1.8 \pm 0.1$ fold to $1.2 \pm 0.1$ fold of control. Memantine at $1 \mu \mathrm{M}$ did not elicit protection against $60 \mu \mathrm{M}$ glutamate-mediated activation of caspase-3. 


\subsection{Post-treatment of $L B A$}

In order to examine the possible neuroprotective properties of LBA, post-treatment experiments were performed, in which LBA was added into the culture $1 \mathrm{~h}$ after their exposure to glutamate. Post-treatment of LBA at $100 \mu \mathrm{g} / \mathrm{ml}$ led to a $20.9 \pm 2.4 \%$ and $22.9 \pm$ $3.2 \%$ reduction in $60 \mu \mathrm{M}$ glutamate-triggered $\mathrm{LDH}$ release and activity of caspase-3, respectively (Fig 4c \&d). However, only $250 \mu \mathrm{g} / \mathrm{ml}$ of LBA could significantly attenuate caspase- 3 activity triggered by $30 \mu \mathrm{M}$ glutamate (Fig $4 \mathrm{~b}$ ). We are surprised that protective behavioral in pretreatment and post-treatment was very different, further suggested that the mechanisms of necrosis was different to that of apoptosis. Furthermore, it appeared that 30 $\mu \mathrm{M}$ and $60 \mu \mathrm{M}$ glutamate utilized different toxic pathways for toxic effects. When the protective effects between the pretreatment and post-treatment experiments were compared, we found that pretreatment was more effective than post-treatment.

\subsection{LBA attenuated NMDA-induced neuronal cell death}

Previous studies suggested that activation of NMDA receptor is a key factor for glutamate neurotoxicity (Coyle and Puttfarcken, 1993). In order to find out whether LBA could protect neurons against NMDA-induced neuronal damage, neurons were treated with LBA and then NMDA. After $24 \mathrm{~h}$ of 40 or $60 \mu \mathrm{M}$ NMDA exposure, there were increase in LDH release for $1.4 \pm 0.1$ or $1.6 \pm 0.1$ fold of control, respectively (Fig. 5a). LBA significantly attenuated NMDA-triggered LDH release in dose-dependent manner. Exposure of neurons to 40 or $60 \mu \mathrm{M}$ NMDA-induced apoptosis as indicated by the elevation of the activity of caspase-3 by $1.4 \pm 0.1$ or $1.7 \pm 0.1$ fold of control, respectively (Fig. 5b). LBA significantly attenuated the activity of caspase- 3 induced by $60 \mu \mathrm{M}$ NMDA. However, LBA could not significantly inhibit caspase-3 triggered by $40 \mu \mathrm{M}$ NMDA. Similar to what we 
observed in glutamate, the mechanisms mediating necrosis and apoptosis are somewhat different. Furthermore, it was possible that different pathways mediating low or high concentration of NMDA toxicity.

\subsection{LBA did not function as anti-oxidant}

Oxidative stress is one of the secondary factors mediating glutamate neurotoxicity; and therefore it is a possible therapeutic target. One may suspect of whether LBA have antioxidative properties which would account for its protective effects. In order to investigate this property, we examined if LBA could protect neurons against hydrogen peroxide, a typical oxidative stress inducer. As indicated in Fig. 6, hydrogen peroxide induced neuronal damage as reflected by an increase in LDH release and caspase- 3 activity by $1.3 \pm 0.1$ and $1.5 \pm 0.1$ folds of control, respectively. LBA did not exert protective effect against hydrogen peroxide. In contrast to have no protective effects on $\mathrm{H}_{2} \mathrm{O}_{2}$ toxicity, LBA at 10 or $100 \mu \mathrm{g} / \mathrm{ml}$ significantly increased caspase-3 activity. The results may imply that free radicals may change conformation of LBA at some concentrations to abolish protective effects of LBA.

To further confirm whether LBA suppressed production of free radicals by glutamate, we employed NBT reduction assay to examine intracellular free radicals. Our results showed that there was a 58\% increase of intracellular ROS (Fig. 7). LBA did not attenuate intracellular ROS level, which further support the notion that LBA did not function as antioxidant to protect neurons in glutamate excitotoxicity.

\subsection{LBA attenuated phosphorylation of JNK triggered by glutamate}

JNK has been shown to be one of the signaling pathways being activated by glutamate (Arthur et al., 2007; Chen et al., 2003; Chi et al., 2005). Results from Western-blot analysis 
showed that there was a significant increase in phosphorylation of JNK1, with little effect on non-phosphorylated JNK1 (Fig. 8). LBA reduced phosphorylation of JNK1 dose-dependently and this was consistent with its protective effects. 


\section{Discussion}

In this study, we have demonstrated that exposure of primary cortical neurons to LBA prevents neuronal damage induced by glutamate and NMDA. Since disturbance of glutamate transmission is one of the pathological factors in dementia and degenerative processes, attenuation of glutamate excitotoxicity by LBA is an advantage to stop progression of disease. Therefore, we provide evidence here that LBA can be further explored of whether it can be developed as a potential candidate as disease-modifying agent for the treatment of AD.

It has been documented that glutamate can impose its toxicity on neurons in both necrotic and apoptotic manner (Portera-Cailliau et al., 1997; Arthur et al., 2007; Kogo et al., 2006). Our results indicate that excitotoxic glutamate triggered release of LDH from neurons; and this is significantly blocked by LBA. LBA also attenuates NMDA toxicity as reflected by the attenuation of the release of LDH. With the use of NMDA antagonist MK801, we found that glutamate neurotoxicity was attenuated (data not shown). This suggests that NR2A receptor pathway took part, at least in some degree, in glutamate-mediated excitotoxicity in our model.

Activation of caspases is believed to play a key role in glutamate-induced neuronal apoptosis (Zhang and Bhavnani, 2006; Amodio et al., 2006). In agreement with previous studies, which show activation of caspase-3 in cortical, hippocampal (Zhang et al., 2003) and cerebellar granular cells (Amodio et al., 2006), our results also show activation of caspase-3. Inhibition of caspase- 3 activation by LBA may partly contribute to its neuroprotective effects against glutamate-triggered neuronal apoptosis. 
Generation of ROS is one of the pathological events during excitotoxicity. Following influx of $\mathrm{Ca}^{2+}$, there are activation of phospholipase and NO synthase, resulting in high levels of ROS and NO. The interaction of NO with superoxide radical leads to formation of reactive peroxynitrite, which can be a cytotoxic mediator in excitatory neuronal injury (Gilgun-Sherki et al., 2002). Since many herbal extracts have anti-oxidative properties, it is reasonable for one to speculate that LBA may exert its protective effects by attenuating ROS generated by glutamate. We found that LBA could not attenuate hydrogen peroxide toxicity, suggesting that LBA may not provide strong anti-oxidative effects. At the same time, we found that LBA treatment could not attenuate glutamate-induced ROS generation, which support the idea that LBA may protect neurons independent on the anti-oxidative mechanism.

We further examined signaling pathways that are mediated by LBA for its protection. Our previous study on LBA has demonstrated that it has anti-apoptotic properties on A $\beta$ induced neuronal cell death, and this is probably mediated by of the JNK signaling pathway (Yu et al., 2005). In fact, active JNK has been implicated in neuronal cell death under different pathological insults such as stroke, epilepsy, traumatic brain injury and neurodegenerative diseases (Choi, 1988). Similar to a previous report (Chen et al., 2003), glutamate induces JNK1 phosphorylation at Thr 183 or Thr 185, with little changes in the phosphorylation of JNK2. Since activation of glutamate receptors mediates physiological functions other than its excitotoxicity, it has been suggested that downstream signaling events rather than blockage of the receptors should be targeted (Borsello et al., 2003). Furthermore, there are reports showing that strong NMDA antagonist such as MK801 (dizocilpine) and phencyclidine can attenuate excitotoxicity; but in the same time induce adverse side effects (Gladstone et al., 2002). Our results of LBA on suppression of JNK activation suggested that it can be a potential candidate for therapeutic purpose. 
In this study, we chose memantine as a positive control and compared its protective effect against glutamate neurotoxicity to that provided by LBA. We chose memantine instead of other traditional extracts for comparison because memantine is a well defined compound and it is an approved drug for the treatment of $\mathrm{AD}$. More importantly, its pharmacokinetic properties had been well studied (Kornhuber et al., 2007). The normal plasma concentration of memantine is $0.5-1 \mu \mathrm{M}$, higher concentrations might increase the chance of adverse effects (Freudenthaler and Pantev, 2008). Our data showed that the neuroprotective effects of LBA against glutamate were comparable to that provided by highest dosage of memantine used in this study. Although we compared LBA with memantine, our present data are not sufficient to state that LBA functions as another NR2A antagonist or receptor modifier. Whether LBA interferes with glutamate receptor functions remains unclear. Previous studies have shown that LBA had diverse protective effects against neuronal damage induced by A $\beta$ peptide as well as dithiothreitol (DTT) (Yu et al., 2005; Yu et al., 2006), it is possible that LBA mediates its protection in the receptor level. Polysaccharide is the major active component in LBA. Recent research suggested that polysaccharide has various effects on the CNS and is involved in long term potentiation, receptor regulation and neuronal development (Lauri et al., 1999; Sotogaku et al., 2007). Regarding the receptor interaction, several reports have demonstrated that polysaccharide is able to modify receptor properties (Sinnarajah et al., 1999; Suppiramaniam et al., 2006). For instant, dextran sulfate, a polyanion that mimics natural mucopolysacchardies such as heparin sulfate, is able to alter binding and channel properties of AMPA receptors (Chicoine et al., 2004). Apart from neuronal damage, over-stimulation on AMPA receptors may also play a role in maintenance and repair of neurons (Dicou et al., 2003; Wu et al., 2004). Recent study has shown that polysaccharide can promote neuroprotection against excitotoxicity by modulating the AMPA receptor signals (Chicoine 
and Bahr, 2007). It is therefore possible for other neuroprotective polysaccharide to protect neurons through modulation of AMPA receptor. More importantly, it has been documented that neuroprotective polysaccharide such as haparin derivatives are able to pass through the blood brain barrier (BBB) (Leveugle et al., 1998; Ma et al., 2002). Whether LBA is also able to pass through $\mathrm{BBB}$ and interferes $\mathrm{AMPA}$ receptor has beyond the scope of our study, but this certainly deserves further investigation.

We have demonstrated that LBA is able to reduce glutamate-induced neuronal damage. Together with our previous findings that it has neuroprotective effects against $A \beta$ toxicity, we propose LBA has multiple benefits on the CNS. Its property of attenuating glutamate toxicity enables it to extend its potential as disease-modifying agent for the treatment of a variety of neurological disorders such as stroke, AD and glaucoma. In fact, our recent results have shown that LBA provides protection for retinal ganglion cells in experimental glaucoma (Chan et al., 2007). Furthermore, its protective effect against glutamate is comparable to that of memantine, a drug that have been approved for treatment of AD. In summary, our findings support the potential therapeutic use of LBA in neurological disorders, and more research is needed to further explore its protective effects and underlying mechanisms. 


\section{Experimental Procedures}

\subsection{Materials}

Wolfberry was purchased from Ning Xia Huizu Autonomous Region. The glycosyl composition and amino acid composition analysis were performed as described in $\mathrm{Yu}$ et al (2005).

Neurobasal $^{\mathrm{TM}}$ medium, B-27 supplement, penicillin, streptomycin and glutamine were purchased from Gibco-BRL (Burligton, Ontario, Canada). Other chemicals were obtained from the following companies: L-glutamate, N-methyl-D-aspartate (NMDA), memantine, nitroblue tetrazolium (NBT) tablet, protease inhibitor cocktail, phosphatase inhibitor cocktail and anti- $\beta$-actin monoclonal antibody were obtained from Sigma-Aldrich, Inc. (St. Louis, MO, USA). Hydrogen peroxide was from BDH Laboratory Supplies (England). Lactate dehydrogenase (LDH) cytotoxicity assay kit was from Roche Diagnostics (Mannheim, Germany). Caspase-3 substrate (Ac-DEVE-pNA) was obtained from Calbiochem, Inc. (La Jolla, CA, USA). Rabbit polyclonal antibodies for JNK detection were purchased from Cell Signaling Technology (Beverly, MA, USA). Horseradish peroxidase-conjugated goat antirabbit and goat anti-mouse antibodies were from DAKO (Glostrup, Denmark). PVDF membrane was from Bio-Rad (Richmond, CA, USA). Biomax X-ray film was from Kodak (Tokyo, Japan). Enhanced chemiluminescence (ECL) detection kit was from Amersham (Buckinghamshire, UK).

\subsection{Preparation of Wolfberry polysacchardes (LBA)}

LBA were prepared according to the previous publication (Yu et al., 2005). In brief, Wolfberry was crushed into small pieces and were extracted with boiling distilled water. After concentration and deproteination by the Sevag method (Seveg, 1934), the resulting aqueous 
fraction was dialyzed, precipitated by ethanol. The retentate were then concentrated and dried to yield a brown powder (LBA).

\subsection{Preparation of primary cortical neurons and treatment}

Cultures of rat embryonic day 17 cortical neurons were prepared as described previously (Chang et al., 2002; Suen et al., 2003). Briefly, cortical neurons were microdissected from the brains of rat fetuses in phosphate-buffered saline (PBS) with glucose (18 $\mathrm{mM}$ ). Cells were subjected to mechanical trituration and were resuspended in Neurobasal ${ }^{\mathrm{TM}}$ medium containing $2 \% \mathrm{~B}-27$, L-glutamine $(2 \mathrm{mM})$, penicillin $(50 \mathrm{U} / \mathrm{ml})$ and streptomycin $(50$ $\mu \mathrm{g} / \mathrm{ml})$. Cells were seeded onto 6-well plates pre-coated with poly-L-lysine $(25 \mu \mathrm{g} / \mathrm{ml})$ at a density of $1.0 \times 10^{6} /$ well. Neurons were maintained at $37^{\circ} \mathrm{C}$ in a humidified atmosphere of $5 \% \mathrm{CO}_{2}$, half of the medium in each well was replaced with fresh medium twice a week. On day 7 in vitro, the cultured cells were treated with different dosages of LBA or memantine prior to the exposure to glutamate, NMDA or hydrogen peroxide for $24 \mathrm{~h}$. For post-treatment, neurons were exposed to glutamate for $1 \mathrm{~h}$ and LBA were subsequently added into the cultures for co-incubation of another $23 \mathrm{~h}$.

\subsection{Assessment of cell death}

Cell death in various treatment groups was determined by the release of LDH into supernatant of cell cultures. Activity of LDH was measured using a commercially available kit as described elsewhere (Lai et al., 2006; Yu et al., 2005). Briefly, equal volume of cell free culture supernatant and assay buffer were transferred into a 96-well-plate and incubated in dark for $30 \mathrm{~min}$ at room temperature. Leakage of LDH into the culture medium was measured at $492 \mathrm{~nm}$ wavelength. Results were expressed as fold of control (fold of control was

calculated as follow: absorbance of glutamate-treated/LBA-treated / absorbance of control). 


\subsection{Assessment of apoptosis}

Apoptotic cell death was determined by measuring the caspase-3-like activity as described elsewhere (Fang et al. 2005; Yu et al. 2007). Proteins were extracted from cortical neurons using lysis buffer ( $5 \mathrm{mM}$ DTT, $0.1 \mathrm{mM}$ EDTA, $50 \mathrm{mM}$ HEPES (pH 7.4) and 0.2\% Triton-X-100) and the supernatant (lysate) was collected. Fifty micrograms of proteins from each sample and caspase-3 substrate (Ac-DEVD-pNA) were transferred to a 96-well-plate and incubated for $2 \mathrm{~h}$ at $37^{\circ} \mathrm{C}$. During the reaction, a yellow product (pNA) was cleaved from the substrate (i.e. DEVD cleavage) and its absorbance at $405 \mathrm{~nm}$ was determined for caspase-3like activity. The values of specific activity (s.a., unit $=\mathrm{pmol} / \mathrm{min} / \mu \mathrm{g}$ ) were calculated. Results were expressed as fold of control.

\subsection{Western blot analysis}

Neurons after treatment were lysed in ice-cold lysis buffer $(10 \mathrm{mM}$ Tris- $\mathrm{HCl}(\mathrm{pH} 7.4)$, $1 \mathrm{mM} \mathrm{NaCl}, 20 \mathrm{mM} \mathrm{Na}{ }_{4} \mathrm{P}_{2} \mathrm{O}_{7}, 2 \mathrm{mM} \mathrm{Na}_{3} \mathrm{VO}_{4}, 1 \%$ Triton-X-100, $10 \%$ glycerol, $0.5 \%$ deoxycholate, $0.1 \%$ SDS, $1 \mathrm{mM}$ phenylmethylsulfonyl fluoride, protease inhibitor cocktail and phosphatase inhibitor cocktail) and the supernatant was collected as described elsewhere (Lai et al. 2008; Suen et al. 2003; Yu et al. 2004). Equal amounts of protein were separated on $12.5 \%$ SDS-polyacrylamide gels and transferred to polyvinylidene difluoride (PVDF) membranes. The membranes were blocked with 5\% non-fat milk in TBST (TBS containing $0.1 \%$ Tween-20). Primary antibody specifically recognizing phosphorylated JNK (1:1000), non-phosphorylated JNK (1:1000) were diluted in TBST and incubated with the membrane overnight. After washing, the membranes were incubated with horseradish peroxidaseconjugated secondary antibodies, and subsequently developed by using the ECL Western blotting detection kit. The membranes were then stripped with stripping buffer $(50 \mathrm{mM}$ 
glycine, $2 \%$ SDS, pH 2.0) and re-probed with monoclonal anti- $\beta$-actin antibody (1:5000) and goat anti-mouse HRP secondary antibody.

\subsection{Determination of ROS level}

Production of ROS intracellularly was determined by the nitroblue tetrazolium (NBT) reduction assay as described previously with some modifications (Choi et al., 2005; McDonald et al., 1997; Chao et al., 2008). The presence of ROS was indicated by the color change of the water soluble NBT (yellow) to insoluble formazan (blue) upon reduction. Cortical neurons were treated with different dosages of LBA for $1 \mathrm{~h}$ prior to the exposure of glutamate. After $2 \mathrm{~h}$ of co-incubation, NBT $(2 \mathrm{mg} / \mathrm{ml})$ was added, and the cells were further incubated for $1 \mathrm{~h}$. Medium was removed and cultures were rinsed twice with ice-cold PBS to remove excess NBT. The intracellular blue formazan was dissolved in dimethylsulfoxide (DMSO) completely by sonication (three pulses of 6s). Samples were centrifuged for 5 min at $13,000 \mathrm{~g}$. The absorbance of the supernatant was determined at $570 \mathrm{~nm}$ in a microplate reader. Results were expressed as fold of control.

\subsection{Statistical analysis}

Data are expressed as mean \pm standard error (SE) from at least 3 independent experiments. The significance of differences among different groups was determined by oneway ANOVA, followed by Student Newman-Keuls as post-hoc test. $\mathrm{P}<0.05$ was considered to be statistically significant. 


\section{Acknowledgments}

The authors would like to thank Professor J. N. Fang for the help in providing LBA. This work is supported by the Research Fund for the Control of Infectious Disease (05050032) from Food and Health Bureau, General Research Grant (7552/06M) and NSFC/RGC Joint Research Scheme (N_HKU707/07M) from Research Grant Council, HKU Alzheimer's Disease Research Network and HKU Seed Funding for Basic Research (200711159028) to RCCC. Also, the work is supported by Azalea 1972 Endowed Fund. WHY would like to thank for the support from the Department of Chemistry. YSH is supported by the Graduate School, MSY is supported by Postdoctoral Fellowship, The University of Hong Kong. 


\section{Figure legends}

Fig. 1. LBA protected cortical neurons from glutamate-induced neurotoxicity. Rat primary cortical neurons were treated with different dosages of LBA for $1 \mathrm{~h}$ and then co-incubated with 30 or $60 \mu \mathrm{M}$ glutamate for $24 \mathrm{~h}$. The level of neuronal cell death in culture treated with (a) LBA only (c) LBA and $30 \mu \mathrm{M}$ glutamate and (e) LBA and $60 \mu \mathrm{M}$ glutamate was accessed by LDH assay. Cultured neurons have a normal turnover with baseline of LDH of $12.5 \pm$ $0.5 \%$ of total lysis. The level of apoptosis in culture treated with (b) LBA only (d) LBA and $30 \mu \mathrm{M}$ glutamate and (f) LBA and $60 \mu \mathrm{M}$ glutamate was accessed by colorimetric caspase-3 like activity assay. The specific activity of caspase- 3 was $0.042 \pm 0.007 \mathrm{pmol} / \mathrm{min} / \mu \mathrm{g}$ of protein in the control group. Data represent mean \pm SE from at least 3 independent experiments. The significance of differences among treatment groups was determined by oneway ANOVA, followed by Student Newman-Keuls as post-hoc test. ${ }^{*} \mathrm{p}<0.001$ compared to control. ${ }^{\Delta} \mathrm{p}<0.05$ compared to cultures treated with $30 \mu \mathrm{M}$ glutamate. ${ }^{* *} \mathrm{p}<0.001$ compared to cultures treated with $60 \mu \mathrm{M}$ glutamate. ${ }^{*} \mathrm{p}<0.05$ compared to cultures treated with $60 \mu \mathrm{M}$ glutamate.

Fig. 2. LBA preserved morphological changes in glutamate-treated groups. Neurons were incubated in the absence or presence of glutamate for $24 \mathrm{~h}$. LBA was added $1 \mathrm{~h}$ before the addition of glutamate. Photographs shows phase-contrast images of representative fields of cells after various treatments. (a) Control, (b) $30 \mu \mathrm{M}$ glutamate, (c) $60 \mu \mathrm{M}$ glutamate, circled areas indicate fragmented neuritis, (d) $500 \mu \mathrm{g} / \mathrm{ml} \mathrm{LBA,} \mathrm{(e)} 500 \mu \mathrm{g} / \mathrm{ml}$ LBA $+30 \mu \mathrm{M}$ glutamate and (f) $500 \mu \mathrm{g} / \mathrm{ml} \mathrm{LBA}+60 \mu \mathrm{M}$ glutamate. There were no obvious morphological difference between the control and LBA alone treatment groups, while LBA preserved the morphology of neurons that exposed to glutamate. 
Fig. 3. Neuroprotective effects of LBA against glutamate toxicity were comparable to that provided by memantine. Neurons were treated with LBA or memantine for $1 \mathrm{~h}$ prior to the addition of glutamate for $24 \mathrm{~h}$. The protective effects of LBA and memantine against glutamate-induced cell death and apoptosis were accessed by (a) LDH assay and (b) caspase-3 like activity assay. Data represent mean \pm SE from at least 3 independent experiments. The significance of differences among treatment groups was determined by one-way ANOVA, followed by Student Newman-Keuls as post-hoc test. ${ }^{\#} \mathrm{p}<0.001$ compared to control. ${ }^{* *} \mathrm{p}<0.001$ compared to cultures treated with $60 \mu \mathrm{M}$ glutamate. ${ }^{*} \mathrm{p}<0.05$ compared to cultures treated with $60 \mu \mathrm{M}$ glutamate. ${ }^{\Delta \Delta} \mathrm{p}<0.001$ compared to cultures treated with $30 \mu \mathrm{M}$ glutamate. ${ }^{\Delta} \mathrm{p}<0.05$ compared to cultures treated with $30 \mu \mathrm{M}$ glutamate.

Fig. 4. Effects of post-treatment of LBA on glutamate neurotoxicity. Neurons were exposed to glutamate for $1 \mathrm{~h}$ prior to LBA for another $23 \mathrm{~h}$. Release of LDH was measured in (a) neurons treated with LBA and $30 \mu \mathrm{M}$ glutamate (c) LBA and $60 \mu \mathrm{M}$ glutamate. Level of apoptosis in (b) neurons treated with LBA and $30 \mu \mathrm{M}$ glutamate (d) LBA and $60 \mu \mathrm{M}$ glutamate was accessed by measuring the caspase- 3 like activity. Data were analyzed by oneway ANOVA for multiple comparisons, followed by Student Newman-Keuls as post-hoc test. ${ }^{\#} \mathrm{p}<0.001$ compared to control. ${ }^{\Delta \Delta} \mathrm{p}<0.001$ compared to cultures treated with $30 \mu \mathrm{M}$ glutamate. ${ }_{\mathrm{p}}<0.05$ compared to cultures treated with $30 \mu \mathrm{M}$ glutamate. ${ }^{*} \mathrm{p}<0.05$ compared to cultures treated with $60 \mu \mathrm{M}$ glutamate.

Fig. 5. Effects of LBA against NMDA neurotoxicity. LBA was added into the culture for $1 \mathrm{~h}$ and then co-incubated with 40 or $60 \mu \mathrm{M}$ NMDA for $24 \mathrm{~h}$. (a) LDH assay and (b) caspase-3 like activity assay were performed. Data represent mean \pm SE from at least 3 independent experiments. The significance of differences among treatment groups was determined by one- 
way ANOVA, followed by Student Newman-Keuls as post-hoc test. ${ }^{*} \mathrm{p}<0.001$ compared to control. ${ }^{\#} \mathrm{p}<0.05$ compared to control. ${ }^{\Delta \Delta} \mathrm{p}<0.001$ compared to cultures treated with $40 \mu \mathrm{M}$ NMDA. ${ }^{* *} \mathrm{p}<0.001$ compared to cultures treated with $60 \mu \mathrm{M}$ NMDA.

Fig. 6. LBA could not protect neurons against $\mathrm{H}_{2} \mathrm{O}_{2}$-induced toxicity. Neurons were treated with LBA for $1 \mathrm{~h}$ prior to the exposure to $\mathrm{H}_{2} \mathrm{O}_{2}$ for $24 \mathrm{~h}$. (a) LDH assay and (b) caspase-3 like assay were carried out to examine its protective effect. Data represent mean $\pm \mathrm{SE}$ from at least 3 independent experiments. The significance of differences among treatment groups was determined by one-way ANOVA, followed by Student Newman-Keuls as post-hoc test. ${ }^{\#} \mathrm{p}<0.001$ compared to control. ${ }^{*} \mathrm{p}<0.05$ compared to cultures treated with $\mathrm{H}_{2} \mathrm{O}_{2}$.

Fig. 7. LBA did not attenuate glutamate-induced production of ROS. Neurons were treated with LBA for $1 \mathrm{~h}$ prior to the exposure to $60 \mu \mathrm{M}$ glutamate for $2 \mathrm{~h}$. NBT reduction assay were performed to access the level of intracellular ROS. Data represent mean \pm SE from at least 3 independent experiments. The significance of differences among treatment groups was determined by one-way ANOVA, followed by Student Newman-Keuls as post-hoc test. ${ }^{\#} \mathrm{p}<0.001$ compared to control. ${ }^{*} \mathrm{p}<0.05$ compared to cultures treated with glutamate only.

Fig. 8. LBA suppressed the phosphorylation of $\mathrm{JNK}$ in glutamate-treated groups. Neurons were treated with indicated dosages of LBA for $1 \mathrm{~h}$ prior to the exposure to $60 \mu \mathrm{M}$ glutamate for $2 \mathrm{~h}$. Cell were harvested for measurement of phosphorylated JNK and non-phosphorylated JNK by Western blotting. $\beta$-Actin was used as internal control. The images of Western blots films were scanned and quantified with Image J. Data showed the ratio of p-JNK to JNK. Data represent mean \pm SE from at least 3 independent experiments. Statistical analysis was 
performed with one-way ANOVA, followed by Student Newman-Keuls as post-hoc test. ${ }^{\#} \mathrm{p}<0.05$ compared to control. ${ }^{*} \mathrm{p}<0.05$ compared to cultures treated with $60 \mu \mathrm{M}$ glutamate. 


\section{References}

Abib RT, Quincozes-Santos A, Nardin P, Wofchuk ST, Perry ML, Gonçalves. C.A., Gottfried C (2008) Epicatechin gallate increases glutamate uptake and S100B secretion in C6 cell lineage. Mol Cell Biochem. 310:153-158.

Amagase H, Nance DM (2008) A Randomized, Double-Blind, Placebo-Controlled, Clinical Study of the General Effects of a Standardized Lycium barbarum (Goji) Juice, GoChi. J Altern Complement Med In press

Amodio R, Esposito E, De RC, Bellavia V, Amodio E, Carruba G, (2006) Red wine extract prevents neuronal apoptosis in vitro and reduces mortality of transgenic mice. Ann NY Acad Sci 1089,:88-97.

Arthur PG, Matich GP, Pang WW, Yu DY, Bogoyevitch MA, (2007) Necrotic death of neurons following an excitotoxic insult is prevented by a peptide inhibitor of c-jun $\mathrm{N}$ terminal kinase. J Neurochem 102:65-76.

Arundine M, Tymianski M, (2004) Molecular mechanisms of glutamate-dependent neurodegeneration in ischemia and traumatic brain injury. Cell Mol Life Sci 61:657-668.

Baethmann A, Staub F, Kempski O, Plesnila N, Chang RCC, Schnezder GH, Eriskat J, Stoffel, M, Ringel F, (1996) Glutamate enhances brain damage from ischemia and trauma. In:"Maturation Phenomenon in cerebral ischemia II", (Ito U, ed) Berlin, Springer-Venlag, pp43-51.

Borsello T, Clarke PG, Hirt L, Vercelli A, Repici M, Schorderet DF, Bogousslavsky J, Bonny, C, (2003) A peptide inhibitor of c-Jun N-terminal kinase protects against excitotoxicity and cerebral ischemia. Nat Med 9:1180-1186.

Chan HC, Chang RCC, Koon-Ching IA, Chiu K, Yuen WH, Zee SY, So KF, (2007) Neuroprotective effects of Lycium barbarum Lynn on protecting retinal ganglion cells in an ocular hypertension model of glaucoma. Exp Neurol 203:269-273.

Chang RCC, So KF, (2008) Use of Anti-aging Herbal Medicine, Lycium barbarum, Against Aging-associated Diseases. What Do We Know So Far? Cell Mol Neurobiol 28:643-652.

Chang RCC, Suen KC, Ma CH, Elyaman W, Ng HK, Hugon J, (2002) Involvement of double-stranded RNA-dependent protein kinase and phosphorylation of eukaryotic initiation factor-2alpha in neuronal degeneration. J Neurochem 83:1215-1225.

Chao J, Yu MS, Ho YS, Wang M, Chang RCC, (2008) Dietary oxyresveratrol prevents parkinsonian mimetic 6-hydroxydopamine neurotoxiciy. Free Rad Biol Med 45:1019-26.

Chen RW, Qin ZH, Ren M, Kanai H, Chalecka-Franaszek E, Leeds P, Chuang DM, (2003) Regulation of c-Jun N-terminal kinase, p38 kinase and AP-1 DNA binding in cultured brain neurons: roles in glutamate excitotoxicity and lithium neuroprotection. $\mathrm{J}$ Neurochem 84:566-575. 
Chi CW, Wang CN, Lin YL, Chen CF, Shiao YJ, (2005) Tournefolic acid B methyl ester attenuates glutamate-induced toxicity by blockade of ROS accumulation and abrogating the activation of caspases and JNK in rat cortical neurons. J Neurochem 92:692-700.

Chicoine LM, Bahr BA, (2007) Excitotoxic protection by polyanionic polysaccharide: evidence of a cell survival pathway involving AMPA receptor-MAPK Interactions. J Neurosci Res 85:294-302.

Chicoine LM, Suppiramaniam V, Vaithianathan T, Gianutsos G, Bahr BA, (2004) Sulfateand size-dependent polysaccharide modulation of AMPA receptor properties. J Neurosci Res 75:408-416.

Choi DW, (1988) Glutamate neurotoxicity and diseases of the nervous system. Neuron 1:623634.

Choi DW, Maulucci-Gedde M, Kriegstein AR, (1987) Glutamate neurotoxicity in cortical cell culture. J Neurosci 7:357-368.

Choi SH, Lee DY, Kim SU, Jin BK, (2005) Thrombin-induced oxidative stress contributes to the death of hippocampal neurons in vivo: role of microglial NADPH oxidase. J Neurosci 25:4082-4090.

Coyle JT, Puttfarcken P, (1993) Oxidative stress, glutamate, and neurodegenerative disorders. Science 262: 689-695.

Dicou E, Rangon CM, Guimiot F, Spedding M, Gressens P, (2003) Positive allosteric modulators of AMPA receptors are neuroprotective against lesions induced by an NMDA agonist in neonatal mouse brain. Brain Res 970:221-225.

Fang X, Yu MM, Yuen WH, Zee SY, Chang RCC, (2005) Immune modulatory effects of Prunella vulgaris L. on monocytes/macrophages. Intl J Mol Med 16:1109-1116.

Freudenthaler S, Pantev M, (2008) Dose-response analysis to support dosage recommendations for memantine, Naunyn-Schmiedebergs Arch Pharmacol 353, Suppl.: R159

Gardoni F, Di LM, (2006) New targets for pharmacological intervention in the glutamatergic synapse. Eur J Pharmacol 545:2-10.

Gilgun-Sherki Y, Rosenbaum Z, Melamed E, Offen D, (2002) Antioxidant therapy in acute central nervous system injury: current state. Pharmacol Rev 54:271-284.

Gladstone DJ, Black SE, Hakim AM, (2002) Toward wisdom from failure: lessons from neuroprotective stroke trials and new therapeutic directions. Stroke 33:2123-2136.

Golde TE, (2006) Disease modifying therapy for AD? J Neurochem 99:689-707.

Ho YS, Yu MS, Lai CS, So KF, Yuen WH, Chang RCC, (2007) Characterizing the neuroprotective effects of alkaline extract of Lycium barbarum on beta-amyloid peptide neurotoxicity. Brain Res 1158C:123-134. 
Hyrc K, Handran SD, Rothman SM, Goldberg MP, (1997) Ionized intracellular calcium concentration predicts excitotoxic neuronal death: observations with low-affinity fluorescent calcium indicators. J Neurosci 17:6669-6677.

Johnson JW, Kotermanski SE, (2006) Mechanism of action of memantine. Curr Opin Pharmacol 6:61-67.

Kogo J, Takeba Y, Kumai T, Kitaoka Y, Matsumoto N, Ueno S, Kobayashi S, (2006) Involvement of TNF-alpha in glutamate-induced apoptosis in a differentiated neuronal cell line. Brain Res 1122:201-208.

Kornhuber J, Kennepohl EM, Bleich S, Wiltfang J, Kraus T, Reulbach U, Meineke I, (2007) Memantine pharmacotherapy: a naturalistic study using a population pharmacokinetic approach. Clin Pharmacokinet 46:599-612.

Kornhuber J, Quack G, (1995) Cerebrospinal fluid and serum concentrations of the N-methylD-aspartate (NMDA) receptor antagonist memantine in man. Neurosci Lett 195:137139.

Lai SW, Yu MS, Yuen WH, Chang RCC, (2006) Novel neuroprotective effects of the aqueous extracts from Verbena officinalis Linn. Neuropharmacology 50:641-650.

Lai SW, Yu MS, Yuen WH, So KF, Zee SY, Chang RCC, (2008) Antagonizing beta-amyloid peptide neurotoxicity of the anti-aging fungus Ganoderma lucidum., Brain Res 1190: 215-224.

Lauri SE, Kaukinen S, Kinnunen T, Ylinen A, Imai S, Kaila K, Taira T, Rauvala H, (1999) Reg1ulatory role and molecular interactions of a cell-surface heparan sulfate proteoglycan (N-syndecan) in hippocampal long-term potentiation. J Neurosci 19:12261235 .

Leveugle B, Ding W, Laurence F, Dehouck MP, Scanameo A, Cecchelli R, Fillit H, (1998) Heparin oligosaccharides that pass the blood-brain barrier inhibit beta-amyloid precursor protein secretion and heparin binding to beta-amyloid peptide. J Neurochem 70:736-744.

Li XM, Ma YL, Liu XJ, (2006) Effect of the Lycium barbarum polysaccharides on agerelated oxidative stress in aged mice. J Ethnopharmacol 111:504-511.

Lipton SA, (2005) The molecular basis of memantine action in Alzheimer's disease and other neurologic disorders: low-affinity, uncompetitive antagonism. Curr Alzheimer Res 2:155-165.

Ma Q, Dudas B, Hejna M, Cornelli U, Lee JM, Lorens S, Mervis R, Hanin I, Fareed J, (2002) The blood-brain barrier accessibility of a heparin-derived oligosaccharides $\mathrm{C} 3$. Thromb Res 105:447-453.

McDonald DR, Brunden KR, Landreth GE, (1997) Amyloid fibrils activate tyrosine kinasedependent signaling and superoxide production in microglia. J Neurosci 17:2284-2294.

Miyamoto E, (2006) Molecular mechanism of neuronal plasticity: induction and maintenance of long-term potentiation in the hippocampus. J Pharmacol Sci 100:433-442. 
Parsons CG, Gilling KE, Jatzke C, (2008) Memantine does not show intracellular block of the NMDA receptor channel. Eur J Pharmacol 587:99-103.

Pietrzik C, Behl C, (2005) Concepts for the treatment of Alzheimer's disease: molecular mechanisms and clinical application. Intl J Exp Pathol 86:173-185.

Portera-Cailliau C, Price DL, Martin LJ, (1997) Excitotoxic neuronal death in the immature brain is an apoptosis-necrosis morphological continuum. J Comp Neurol 378:70-87.

Schubert D, Piasecki D, (2001) Oxidative glutamate toxicity can be a component of the excitotoxicity cascade. J Neurosci 21:7455-7462.

Seveg MG, (1934) Deproteinization and removal of capsular polysaccharides, Biochem Z 273:419-423.

Shigeri Y, Seal RP, Shimamoto K, (2004) Molecular pharmacology of glutamate transporters, EAATs and VGLUTs. Brain Res. Brain Res Rev 45:250-265.

Shih AY, Erb H, Sun X, Toda S, Kalivas PW, Murphy TH, (2006) Cystine/glutamate exchange modulates glutathione supply for neuroprotection from oxidative stress and cell proliferation. J Neurosci 26:10514-10523.

Sinnarajah S, Suppiramaniam V, Kumar KP, Hall RA, Bahr BA, Vodyanoy V, (1999) Heparin modulates the single channel kinetics of reconstituted AMPA receptors from rat brain. Synapse 31:203-209.

Sotogaku N, Tully SE, Gama CI, Higashi H, Tanaka M, Hsieh-Wilson LC, Nishi A, (2007) Activation of phospholipase $\mathrm{C}$ pathways by a synthetic chondroitin sulfate-E tetrasaccharide promotes neurite outgrowth of dopaminergic neurons. J Neurochem 103:749-760.

Suen KC, Lin KF, Elyaman W, So KF, Chang RCC, Hugon J, (2003) Reduction of calcium release from the endoplasmic reticulum could only provide partial neuroprotection against beta-amyloid peptide toxicity. J Neurochem 87:1413-1426.

Suppiramaniam V, Vaithianathan T, Manivannan K, Dhanasekaran M, Parameshwaran K, Bahr BA, (2006) Modulatory effects of dextran sulfate and fucoidan on binding and channel properties of AMPA receptors isolated from rat brain. Synapse 60:456-464.

Tan S, Schubert D, Maher P, (2001) Oxytosis: A novel form of programmed cell death. Curr Top Med Chem 1:497-506.

Tan S, Wood M, Maher P, (1998) Oxidative stress induces a form of programmed cell death with characteristics of both apoptosis and necrosis in neuronal cells. J Neurochem 71:95-105.

Won SJ, Kim DY, Gwag BJ, (2002) Cellular and molecular pathways of ischemic neuronal death. J Biochem Mol Biol 35:67-86.

Wu X, Zhu D, Jiang X, Okagaki P, Mearow K, Zhu G, McCall S, Banaudha K, Lipsky RH, Marini AM, (2004) AMPA protects cultured neurons against glutamate excitotoxicity 
through a phosphatidylinositol 3-kinase-dependent activation in extracellular signalregulated kinase to upregulate BDNF gene expression. J Neurochem 90:807-818.

Yazawa K, Kihara T, Shen H, Shimmyo Y, Niidome T, Sugimoto H, (2006) Distinct mechanisms underlie distinct polyphenol-induced neuroprotection. FEBS letters 580:6623-6628.

Yu MS, Ho YS, So KF, Yuen WH, Chang RCC, (2006) Cytoprotective effects of Lycium barbarum against reducing stress on endoplasmic reticulum. Intl J Mol Med 17:11571161.

Yu MS, Lai SW, Lin KF, Fang JN, Yuen WH, Chang RCC, (2004) Characterization of polysaccharides from the flowers of Nerium indicum and their neuroprotective effects. Intl J Mol Med 14:917-924.

Yu MS, Leung SK, Lai SW, Che CM, Zee SY, So KF, Yuen WH, Chang RCC, (2005) Neuroprotective effects of anti-aging oriental medicine Lycium barbarum against betaamyloid peptide neurotoxicity. Exp Gerontol 40:716-727.

Yu MS, Wong AY, So KF, Fang JN, Yuen WH, Chang RCC, (2007) New polysaccharide from Nerium indicum protects neurons via stress kinase signaling pathway. Brain Res 1153:221-230.

Zhang Y, Bhavnani BR, (2006) Glutamate-induced apoptosis in neuronal cells is mediated via caspase-dependent and independent mechanisms involving calpain and caspase-3 proteases as well as apoptosis inducing factor (AIF) and this process is inhibited by equine estrogens. BMC Neurosci 7:49.

Zhang Y, Lu X, Bhavnani BR, (2003) Equine estrogens differentially inhibit DNA fragmentation induced by glutamate in neuronal cells by modulation of regulatory proteins involved in programmed cell death. BMC Neurosci 4:32. 
(a)

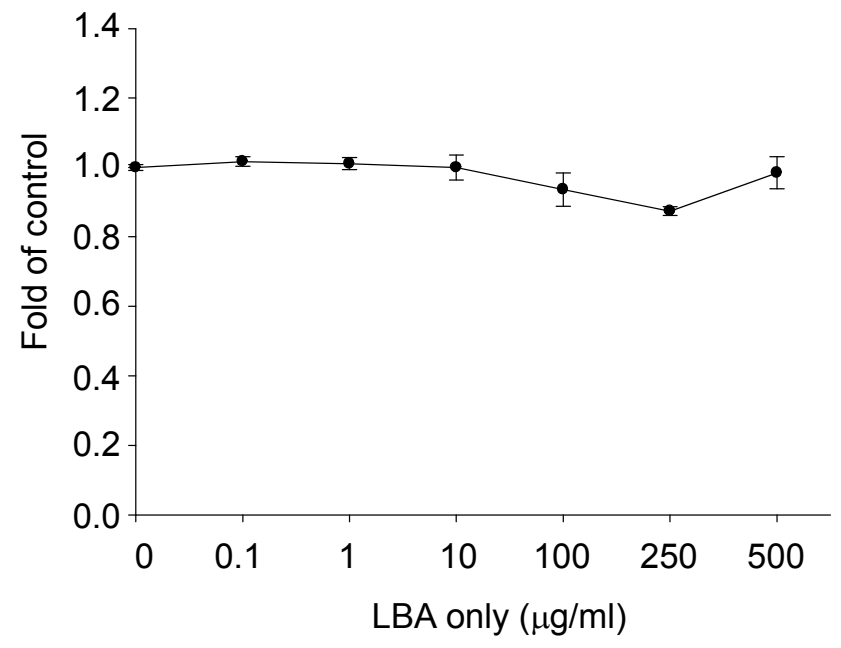

(c)

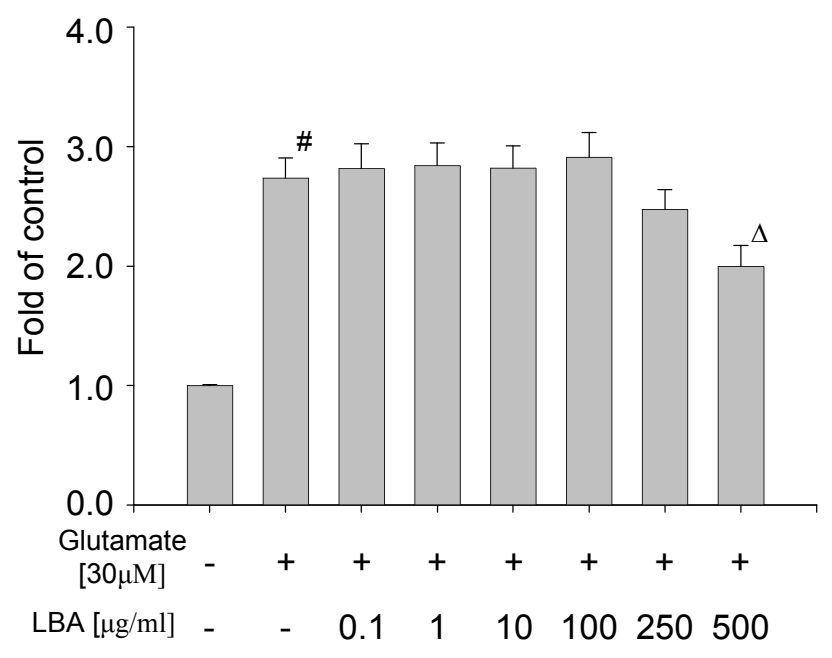

(e)

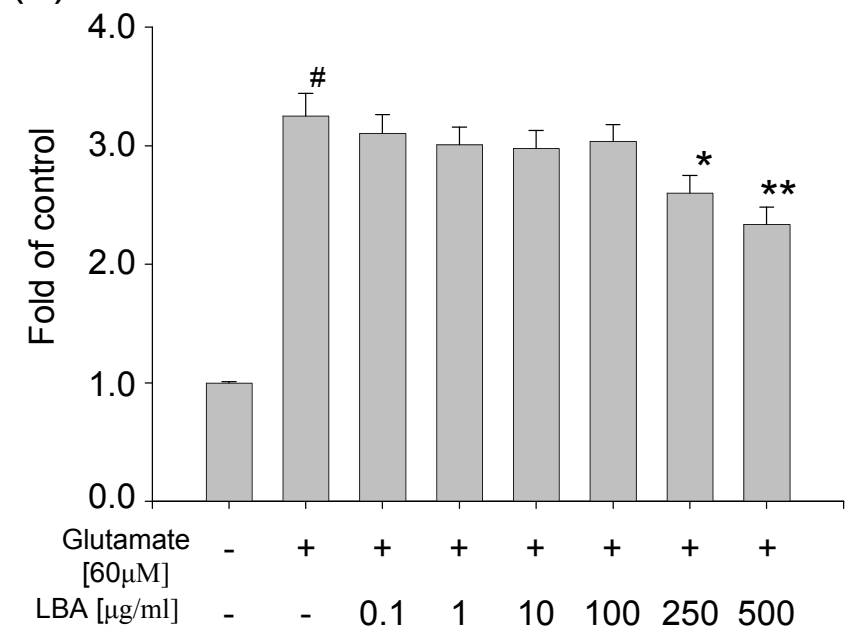

Fig.1 (b)

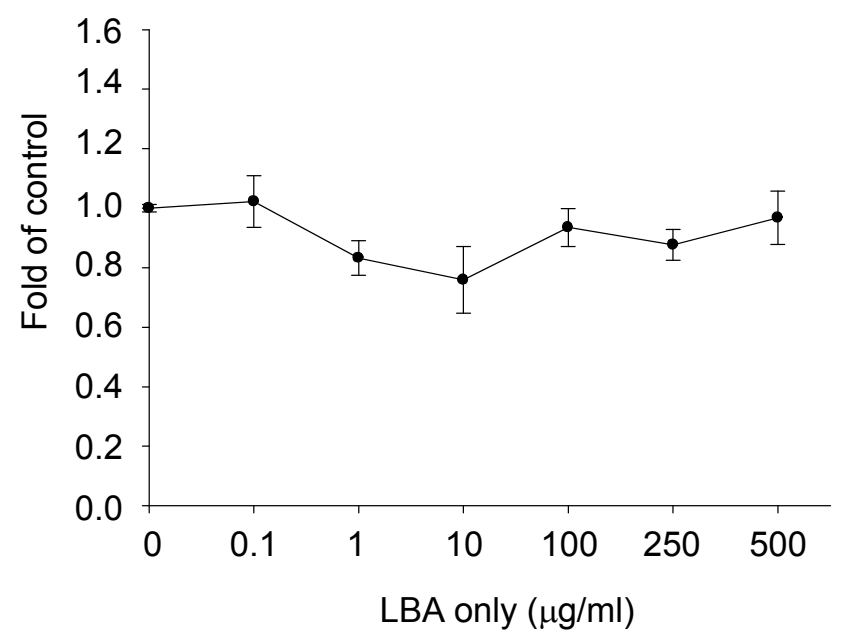

(d)

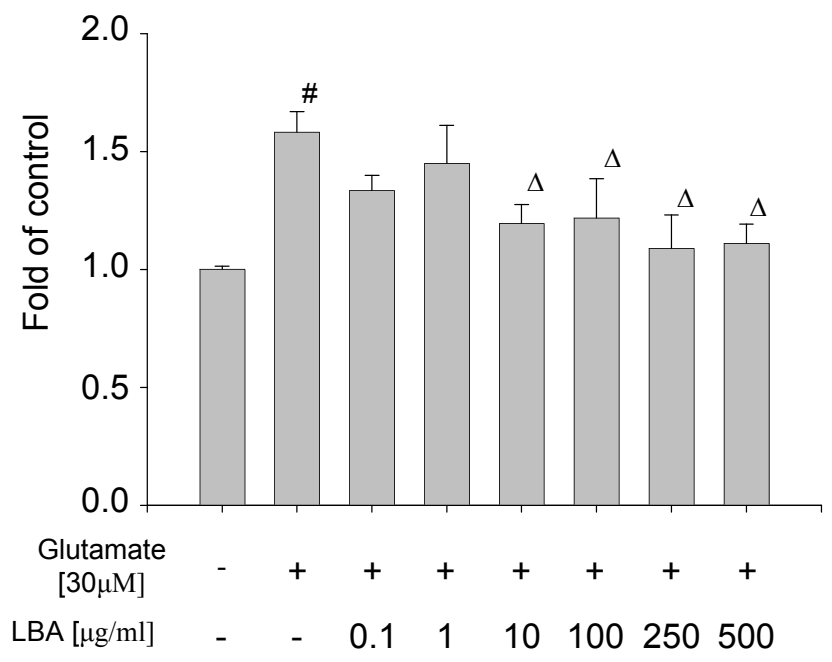

(f)

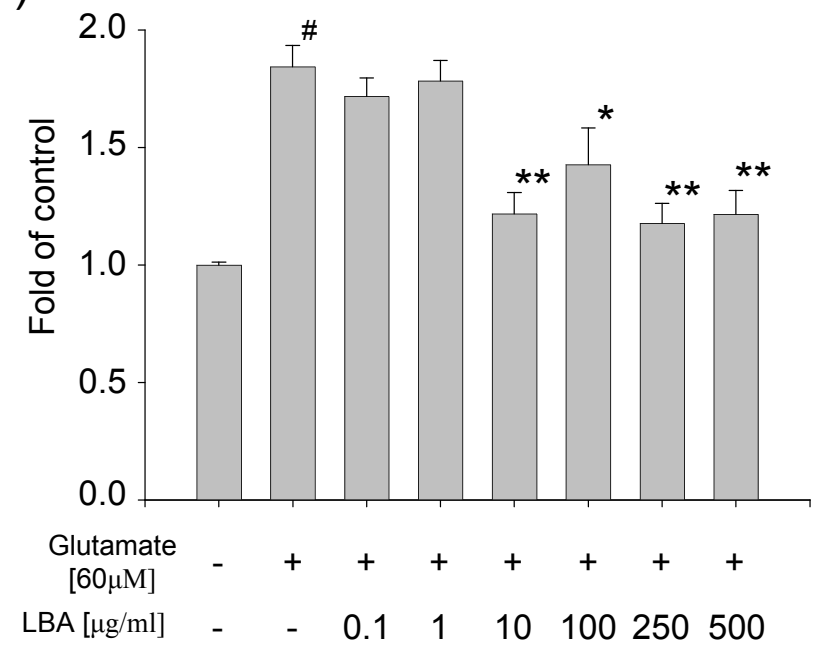



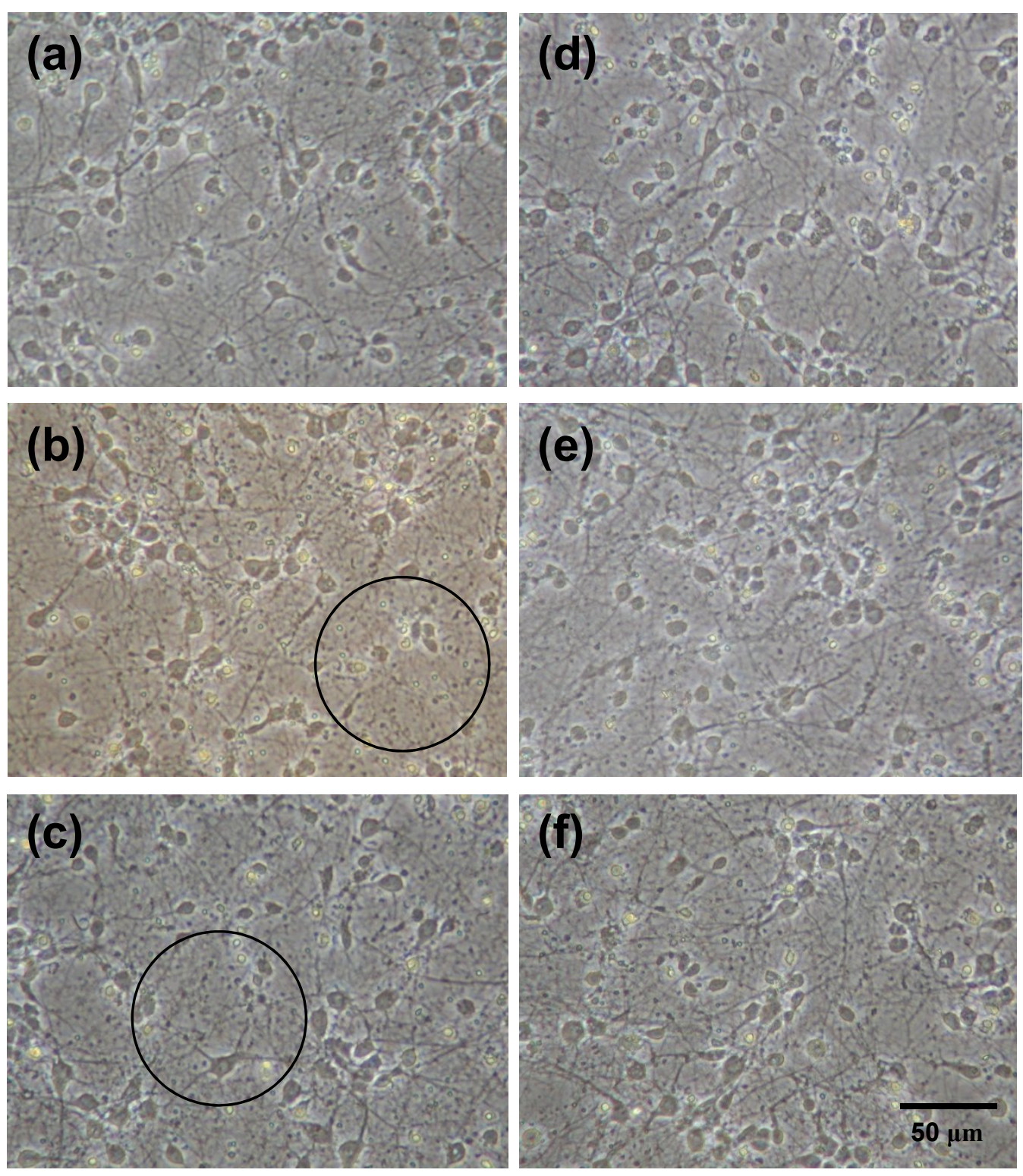

Fig. 2

Ho et. at., 2008 


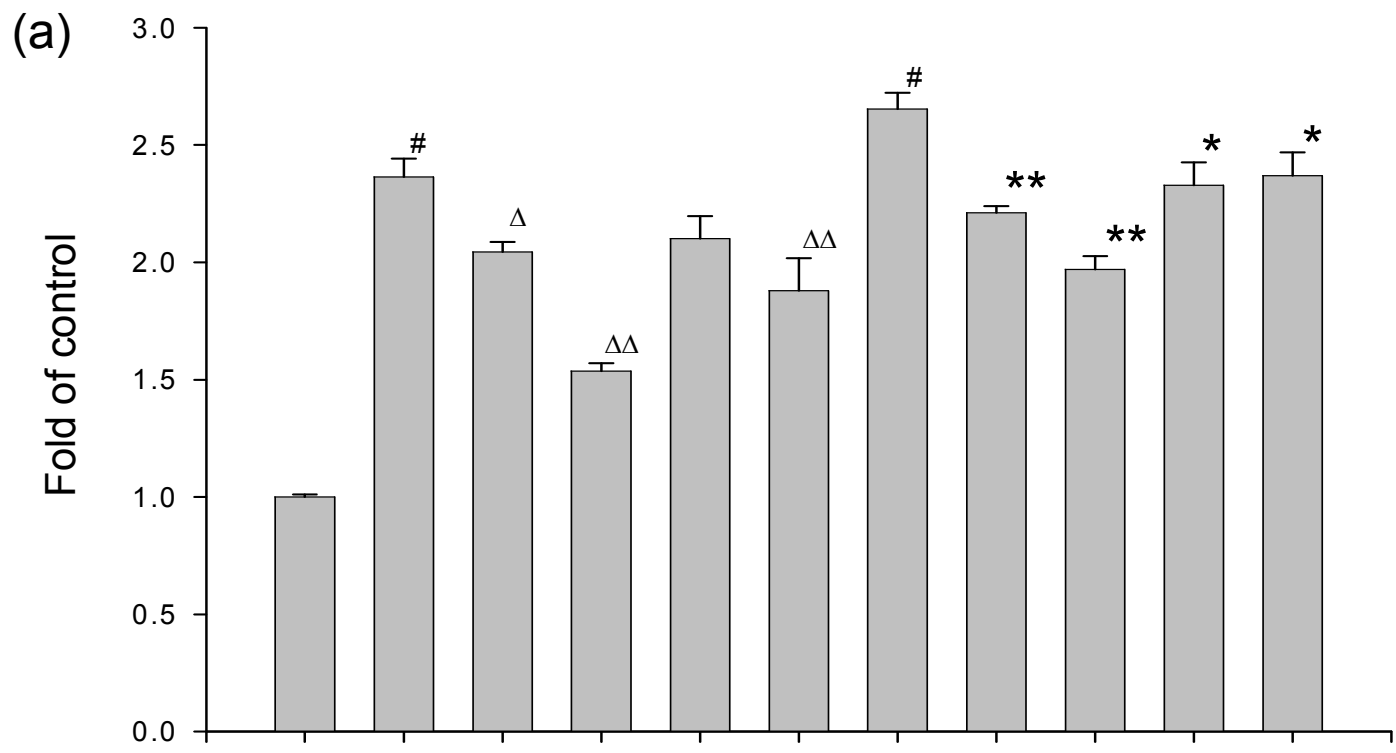

\begin{tabular}{|c|c|c|c|c|c|c|c|c|c|c|c|}
\hline LBA $[\mu \mathrm{g} / \mathrm{ml}]$ & - & - & 250 & 500 & - & - & - & 250 & 500 & - & - \\
\hline Memantine $[\mu \mathrm{M}]$ & - & - & - & - & 0.8 & 1.0 & - & - & - & 0.8 & 1.0 \\
\hline Glutamate $[\mu \mathrm{M}]$ & - & 30 & 30 & 30 & 30 & 30 & 60 & 60 & 60 & 60 & 60 \\
\hline
\end{tabular}

(b)

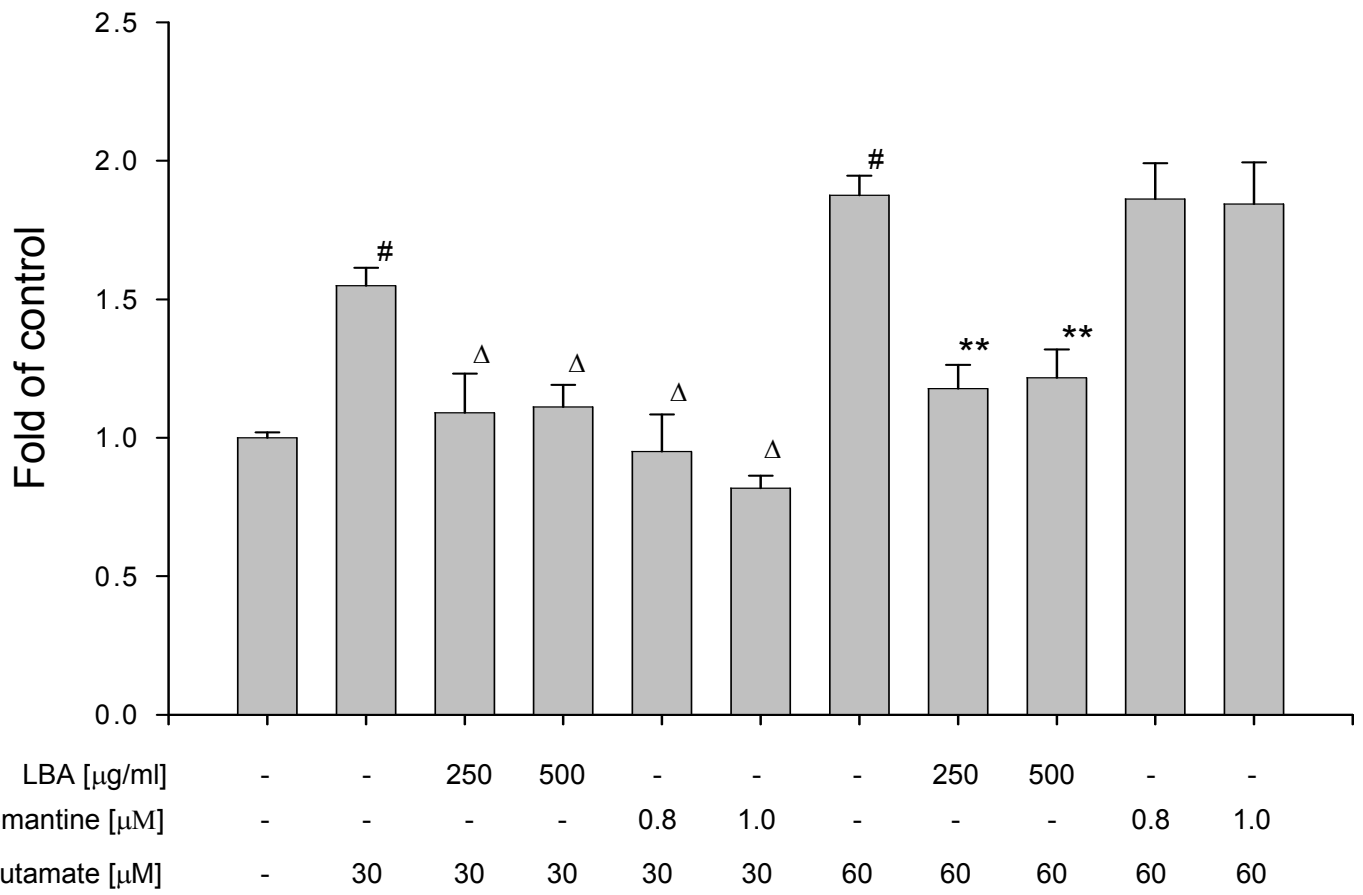

Fig. 3

Ho et. at., 2008 

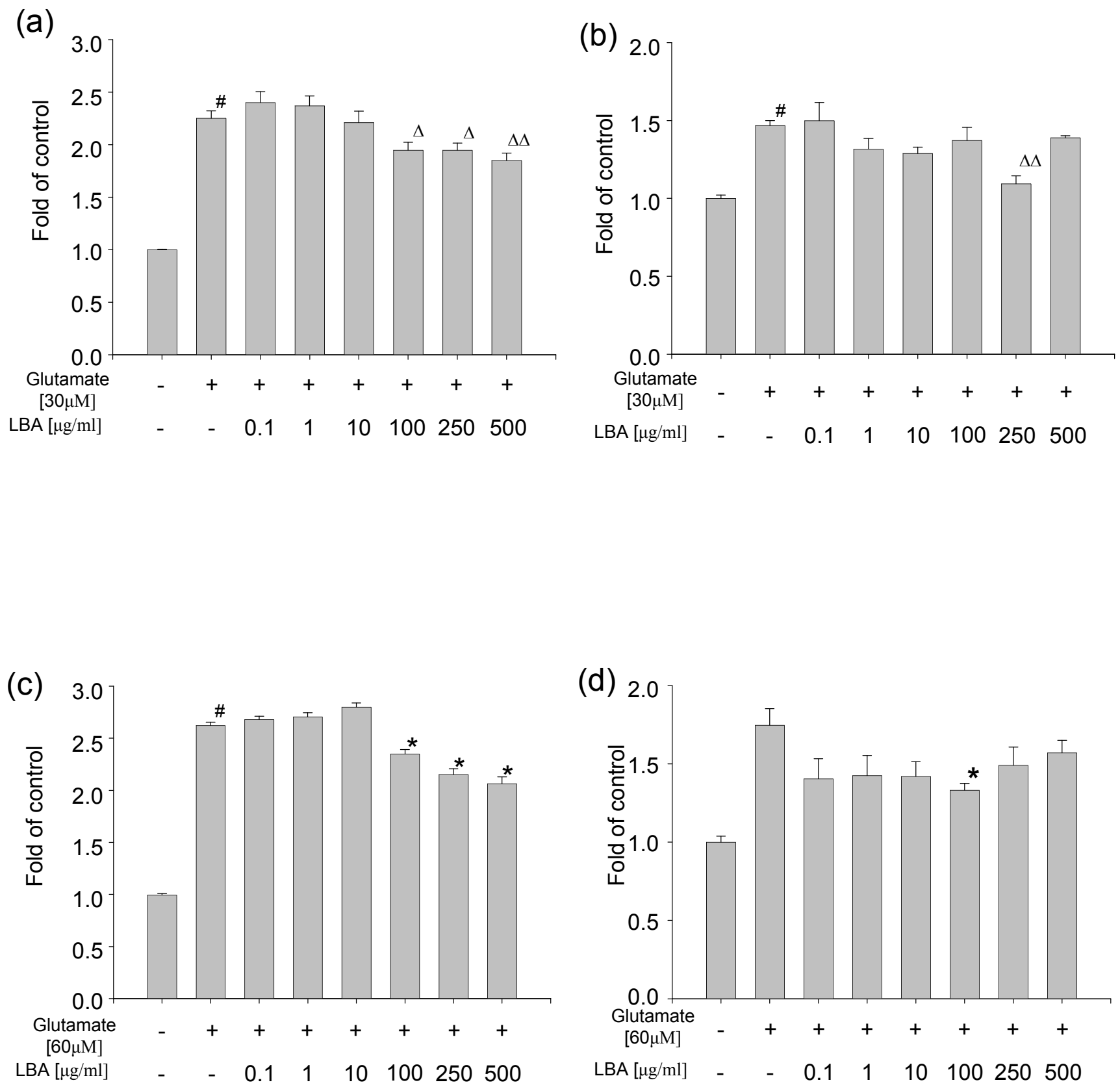

Fig.4 


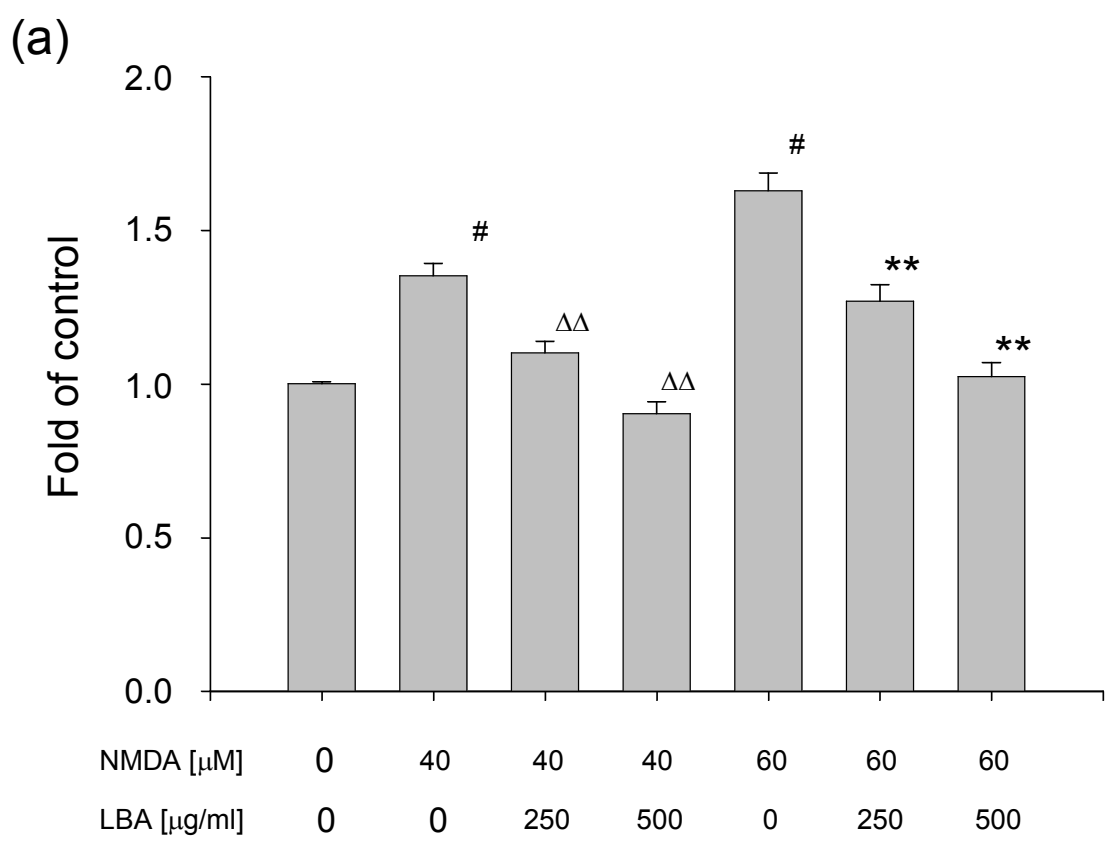

(b)

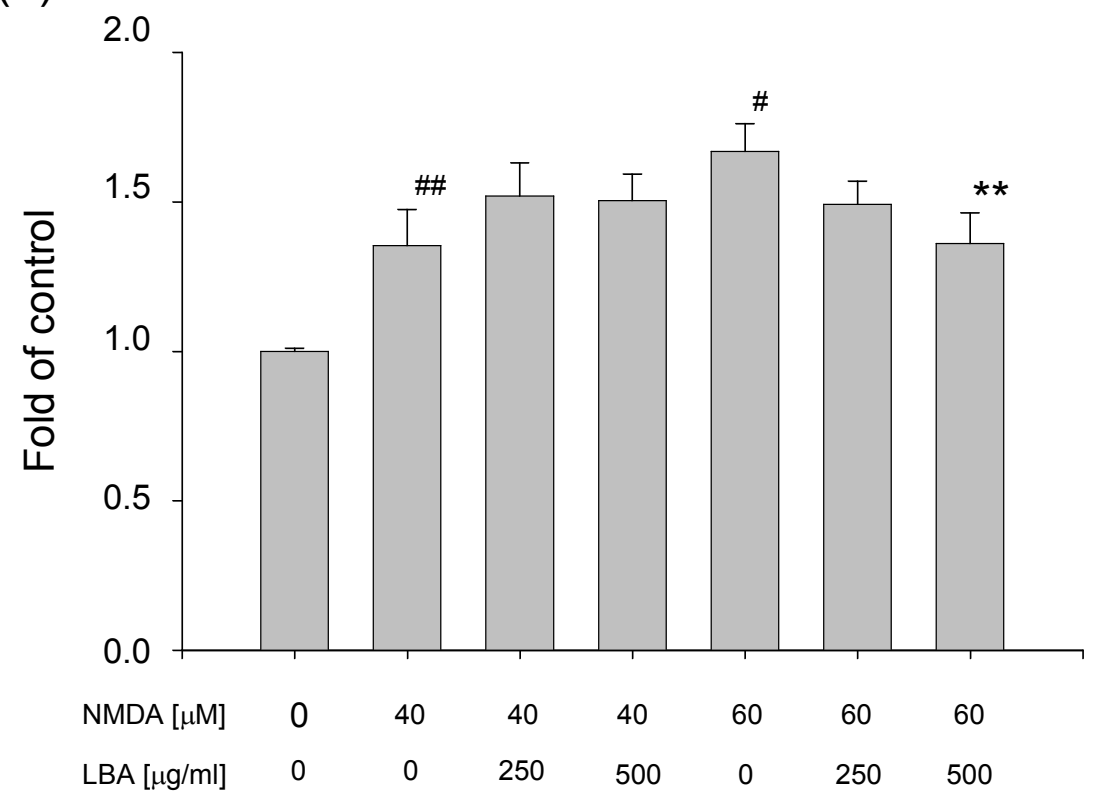

Fig.5

Ho et. at., 2008 
(a)
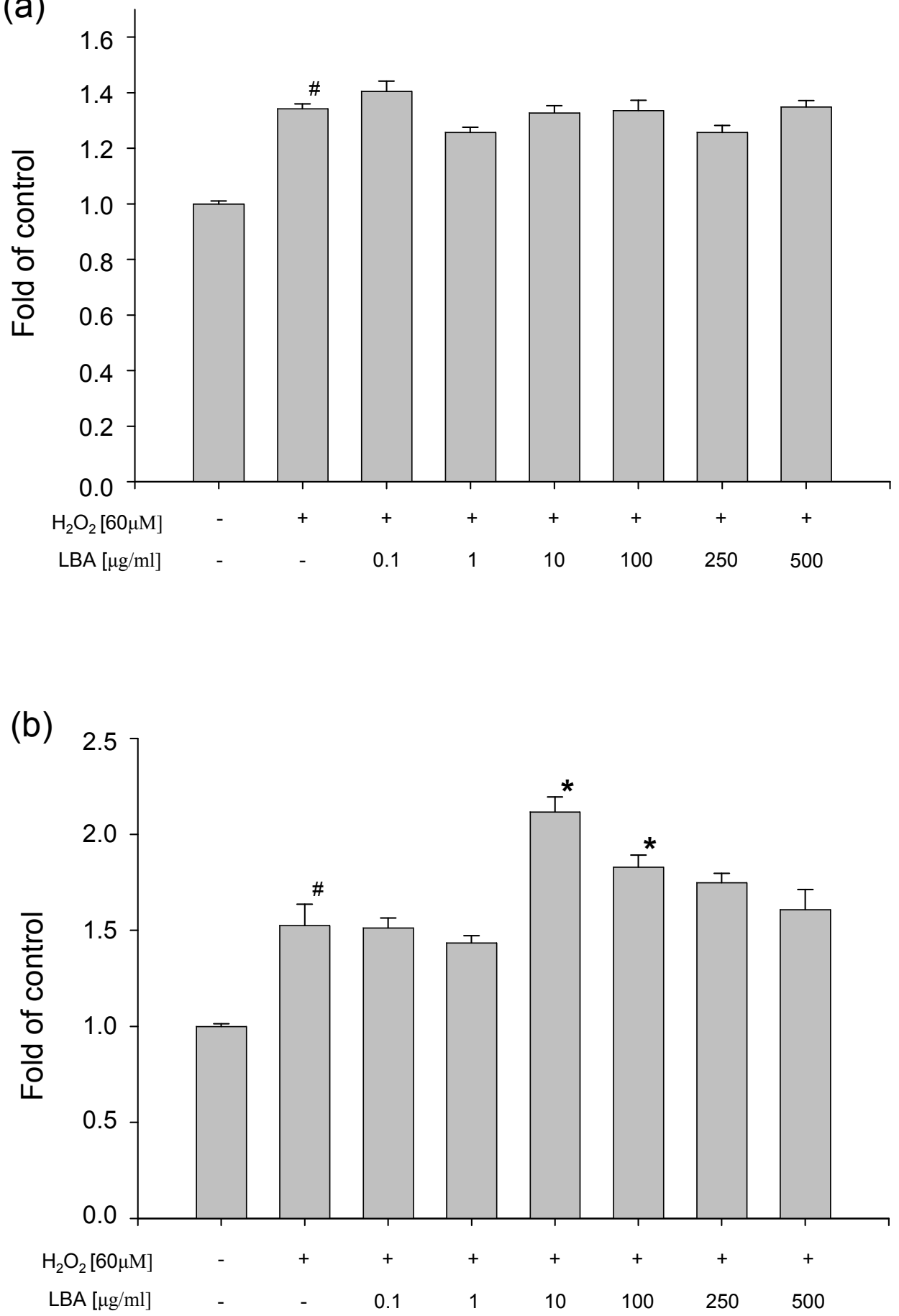

Fig. 6 


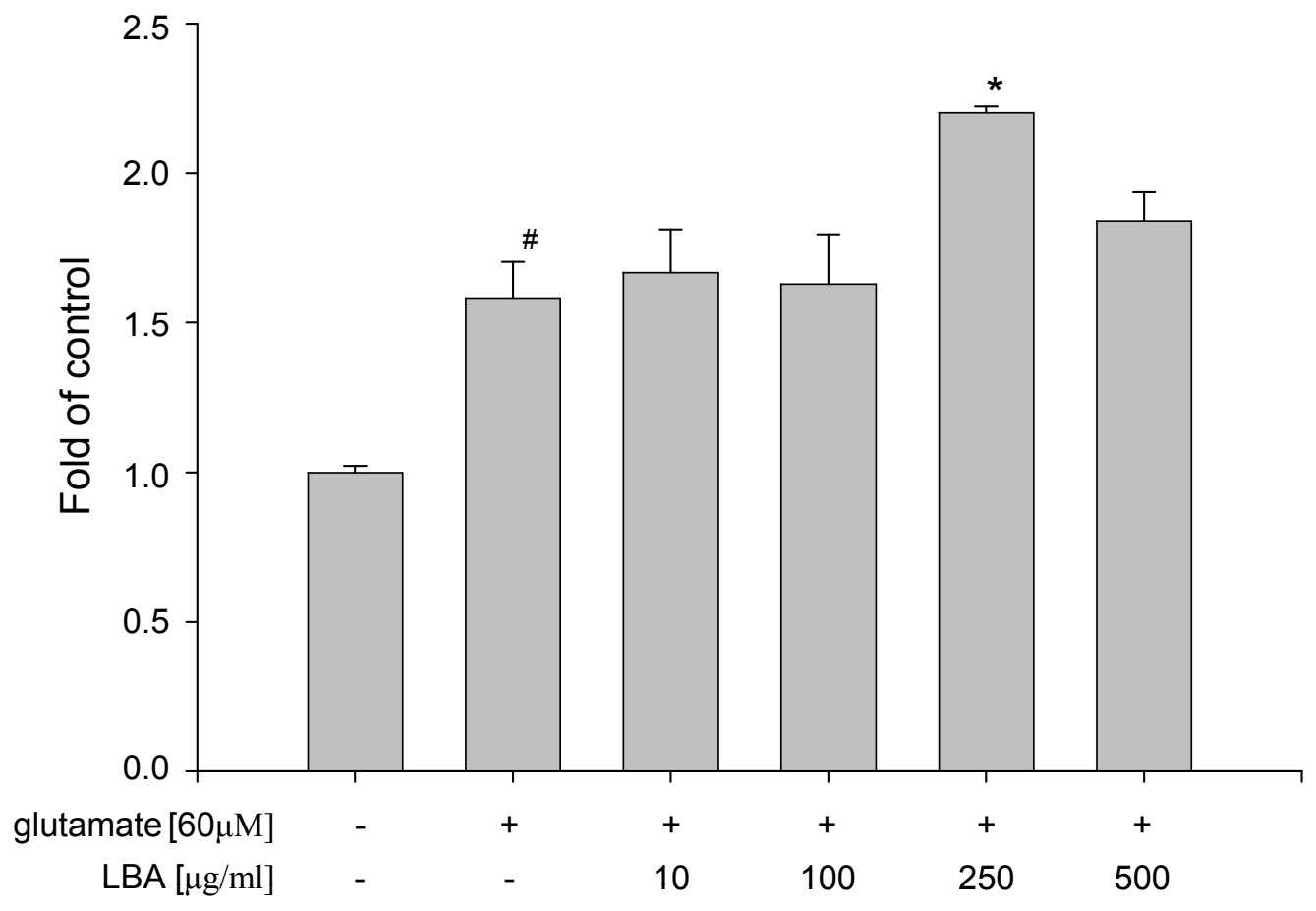

Fig. 7

Ho et. at., 2008 

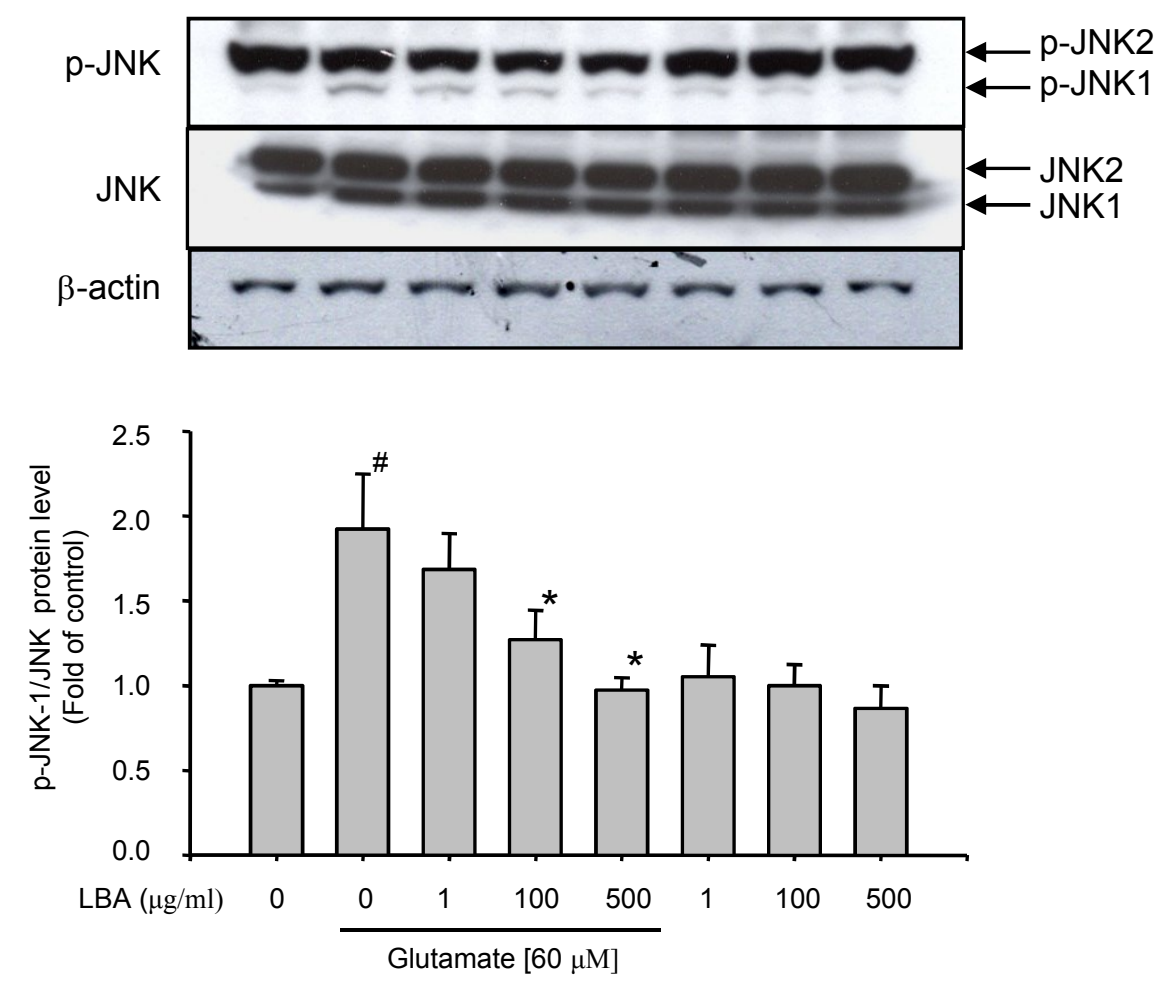

Fig. 8 